\title{
Acalasia en paciente pediátrico: Reporte de caso clínico y revisión de la literatura
}

\author{
Juan Ignacio Errázuriz $B^{(1)}$, Dra Francisca De Barbieri $M^{(2,3)}$.
}

1. Interno de Medicina U. Católica. Santiago - Chile.

2. Médico Radiólogo del Hospital Clínico UC. Santiago - Chile.

3. Departamento de Radiología, Hospital Clínico UC. Santiago - Chile.

\section{Achalasia in a pediatric patient: Case report and literature review}

\begin{abstract}
Achalasia is a rare disease in children. It is an idiopathic disease characterized by loss of normal peristalsis in the distal esophagus and the inability of the lower esophageal sphincter (LES) to relax properly. It presents with dysphagia and weight loss. The imaging study, particularly the study of the esophagus, stomach, duodenum with barium contrast medium, is the diagnostic test of choice, which in $95 \%$ of cases enables a diagnosis. There are various therapeutic options including pneumatic dilation (PD), botulinum toxin injection $(B T)$ and surgery, with the latter giving the best long-term results, the access path is mainly laparoscopic. We report the case of a pediatric patient, evaluated in our department, diagnosed with achalasia.
\end{abstract}

Keywords: Achalasia, Barium esophagram, Pediatric.

Resumen. La acalasia es una enfermedad infrecuente en población pediátrica. Es una enfermedad de causa desconocida que se caracteriza por la pérdida de la peristalsis normal del esófago distal y de la incapacidad del esfínter esofágico inferior de relajarse adecuadamente. El estudio con imágenes, particularmente el estudio del esófago, estómago, duodeno con medio de contraste baritado, es el test de elección, el cual en un 95\% de los casos nos otorga un diagnóstico de certeza. Existen diversas opciones terapéuticas, entre ellas la dilatación neumática, la toxina botulínica y la cirugía, siendo esta última la con mejores resultados a largo plazo, la vía de acceso es principalmente laparoscópica. Presentamos el caso de un paciente pediátrico, evaluado en nuestro departamento, diagnosticado de acalasia.

Palabras clave: Acalasia, Pediátrico, Radiografía esofago-estómago-duodeno.

Errázuriz Jl. Acalasia en paciente pediátrico: Reporte de caso clínico y revisión de la literatura. Rev Radiol 2013; 19(4): 174-176.

Correspondencia: Juan Ignacio Errázuriz Bulnes / jgerrazu@uc.cl

Trabajo recibido el 22 de mayo de 2013. Aceptado el 10 de septiembre de 2013.

\section{Introducción}

La acalasia es una enfermedad infrecuente, con una incidencia aproximada de 1,6 por cada 100.000 , sobre todo antes de la adolescencia donde su presentación es muy rara ${ }^{(2)}$. Esta enfermedad de causa desconocida, se caracteriza por la pérdida de la peristalsis normal del esófago distal y de la incapacidad del esfínter esofágico inferior de relajarse adecuadamente tras la deglución, siendo éste último fenómeno el responsable de los signos y síntomas de la enfermedad.

El estudio con imágenes, particularmente el estudio de esófago-estómago-duodeno con medio de contraste baritado, es el test diagnóstico de elección, el cual en un $95 \%$ de los casos nos otorga un diagnóstico de certeza, solo en caso de duda diagnóstica el estudio se puede complementar con una manometría esofágica.

Existen diversas opciones terapéuticas, entre ellas la dilatación neumática, la toxina botulínica y la cirugía, siendo esta última la con mejores resultados a largo plazo, la vía de acceso es principalmente laparoscópica. Caso Clínico

Paciente de sexo femenino de 9 años, 11 meses, tercera de 4 hermanos, recién nacida de término, con un peso de nacimiento de $3.800 \mathrm{~g}$, sin patología perinatal y con un crecimiento y desarrollo dentro de límites normales, sin antecedentes mórbidos conocidos al momento de la primera consulta.

Consulta por cuadro de un año de evolución de dificultad progresiva para deglutir (disfagia lógica), lo que progresivamente ha limitado su alimentación 
con una baja de peso objetivada de más de un $10 \%$. No presenta vómitos con frecuencia, dolor ni cambios en el tránsito intestinal; tampoco ha presentado síntomas sistémicos como fiebre ni compromiso del estado general. El cuadro clínico hace sospechar una acalasia esofágica.

Se indica estudio con radiografía de esófagoestómago-duodeno, la cual muestra dilatación de los dos tercios distales del esófago, con retención del medio de contraste y formación de un nivel líquido-líquido y disminución aguda del calibre distal con morfología en "pico de pájaro" (Figura 1). Hay marcado retardo del vaciamiento esofágico con paso filiforme del medio de contraste hacia el estómago luego de 4 minutos de observación. La motilidad del esófago está disminuida, sin ondas peristálticas evidentes. Hubo retención del bario en el esófago distal. No se identificaron otras alteraciones anatómicas hacia distal ni episodios de reflujo gastroesofágico espontáneo durante el estudio. El examen es compatible con una acalasia. Por lo que se deriva a cirugía pediátrica para completar estudio $y$ tratamiento.

Es evaluada por el equipo de cirugía pediátrica, quienes inician estudio para una eventual resolución quirúrgica. Se realiza serología de Chagas, que resulta negativa y estudio de laboratorio general para evaluar repercusión nutricional de su presente condición, presentando un valor de albúmina plasmática de 4,5 $\mathrm{gr} / \mathrm{dl}$ y electrolitos plasmáticos dentro de rango, por lo que se decide llevar a cabo una Miotomía de Heller por vía laparoscópica.

\section{Discusión}

La acalasia es una enfermedad infrecuente con una incidencia estimada, reportada en los Estados Unidos de 1,6 casos por cada 100.000. Con la misma frecuencia entre hombres y mujeres, afectando a población de to- das las edades, sin embargo sólo aproximadamente el $10 \%$ de los casos ocurren en población pediátrica y su incidencia antes de la adolescencia es muy infrecuente $^{(1)}$. La fisiopatología, etiología y cuadro clínico de esta enfermedad en niños, es muy similar a la de los adultos.

La acalasia resulta de la degeneración de las neuronas de la pared esofágica ${ }^{(2)}$. A la histología se aprecia una disminución en el número de células ganglionares en el plexo mientérico y las restantes están frecuentemente rodeadas de linfocitos y eosinófilos, afectando principalmente a las células productoras de óxido nítrico implicadas en la inervación inhibitoria del esfínter esofágico inferior ${ }^{(3,4)}$, lo cual causa un aumento en la presión del esfínter y lo vuelve incapaz de relajarse normalmente. En la porción muscular del cuerpo esofágico, la pérdida de esta inervación inhibitoria resulta en aperistalsis.

La causa de la degeneración inflamatoria de las neuronas en la acalasia aún no se conoce. Algunos autores han observado asociación entre la acalasia y el HLA-DQw1 y que los pacientes afectados tendrían anticuerpos circulantes contra las neuronas entéricas, sugierendo un origen autoinmune de la enfermedad ${ }^{(5,6)}$. Otros han propuesto que la acalasia es resultado de la infección crónica por herpes zoster o el virus herpes $1^{(7,8)}$. Sin embargo, todas estas observaciones han sido poco concluyentes.

La mayor parte de las acalasias son idiopáticas, sin embargo, existen algunas patologías que generan anormalidades motoras idénticas o similares a la acalasia, entre ellas el Mal de Chagas, los carcinomas gástricos o esofágicos, esclerodermia, amiloidosis, sarcoidosis, síndrome de Sjogren, entre otros.

Dentro de la sintomatología de la acalasia, lo más propio es disfagia por sólidos y por líquidos, también la mayoría presenta dificultad para eructar.

La baja de peso, regurgitación y dolor torácico ocurren en el $40-60 \%$ de los casos. La baja de peso
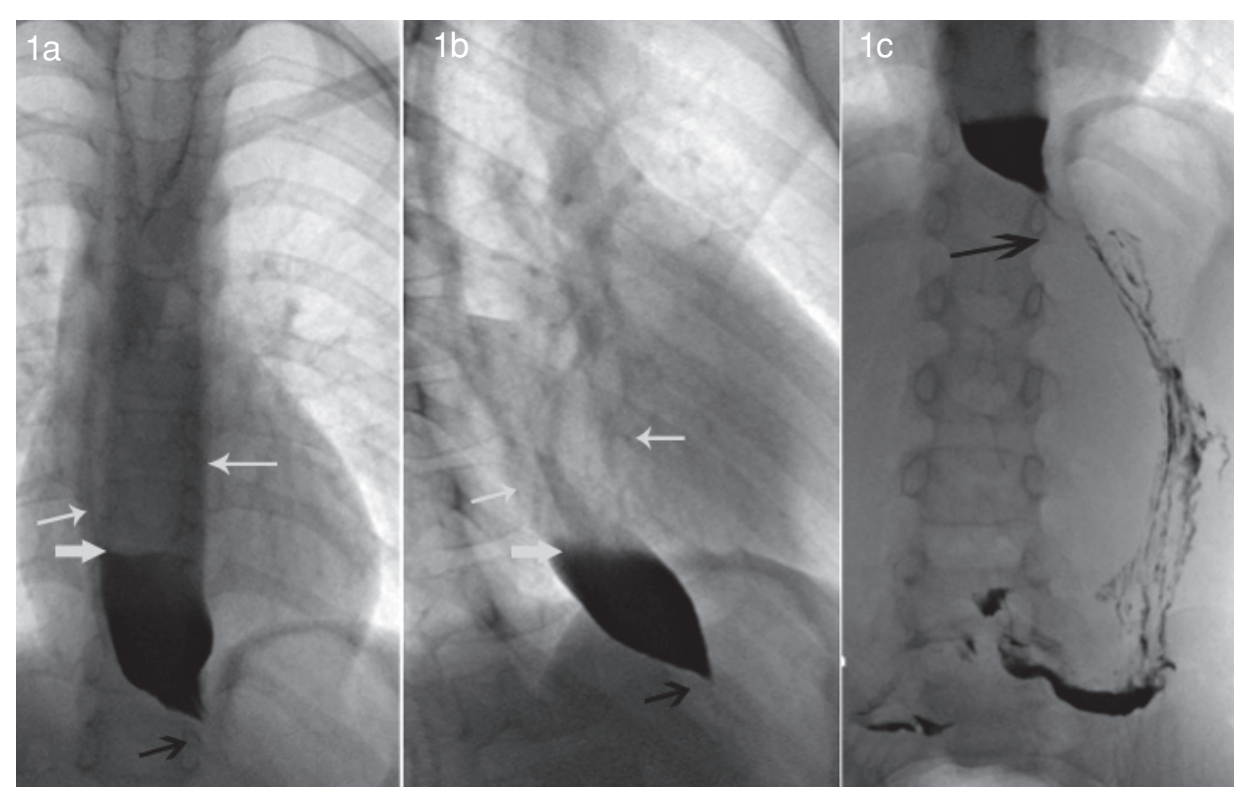

Figura 1. Radiografía de esófago-estómago-duodeno en paciente pediátrico con disfagia, proyección anteroposterior a) Imagen tomada al inicio del estudio, con dilatación distal del esófago (flechas blancas) y retención del medio de contraste con formación de un nivel (cabeza de flecha). Se observa disminución aguda del calibre distal con morfología en "pico de pájaro" (flecha negra). b) A los 2 minutos de estudio, no se observa paso de medio de contraste al estómago. c) A los 4 minutos se observa paso filiforme de contenido a la cámara gástrica (flecha de mayor tamaño). 
no suele ser mayor a 5-10 kg y la regurgitación y dolor al pecho suelen ser en muchos casos el motivo de consulta. Los pacientes suelen alimentarse de manera más lenta y adoptan maniobras específicas para evitar los síntomas al comer.

Los síntomas suelen aparecer de manera insidiosa, por lo que generalmente pasa mucho tiempo antes de que consulten y se haga el diagnóstico ${ }^{(9)}$. Los pacientes con historia sugerente de acalasia deben estudiarse con imágenes y eventualmente con manometría y endoscopía digestiva. El diagnóstico puede sospecharse en una radiografía de tórax simple, en la cual se puede ver el mediastino ensanchado por la dilatación del esófago incluso con nivel hidroaéreo en el interior y ausencia de la burbuja gástrica, ya que la falta de relajación del esfínter no permite el normal paso del aire.

Ante la sospecha clínica, el principal examen diagnóstico es el trago de bario, cuya precisión diagnóstica alcanza hasta $95 \%{ }^{(10)}$. Ésta, típicamente muestra un esófago dilatado que termina con una estrechez con morfología de "pico de pájaro" por la contracción persistente del esfínter esofágico inferior.

Además se puede complementar el estudio con manometrías del esfínter, en casos de duda o para confirmar el diagnóstico, este examen muestra característicamente un aumento de la presión del EEI, con relajación incompleta de éste y aperistalsis del músculo liso(11).

Se sugiere realizar endoscopía en los pacientes con acalasia con factores de riesgo específicos (mayor de 60 años, baja de peso excesiva, antecedentes familiares), para descartar neoplasias digestivas, que pudieran simular una acalasia.

Para el tratamiento de la acalasia existen diversas opciones:

1. Tratamiento médico con nitratos (nifedipino), con resultados heterogéneos, poco consistentes ${ }^{(12)}$.

2. Inyección endoscópica de toxina butolínica, la cual disminuye la presión del EEI. Su efectividad inicial es comparable con la cirugía, sin embargo, los resultados son poco duraderos ${ }^{(13)}$.

3. Dilatación neumática; tratamiento efectivo, sin embargo, su efecto tampoco resulta duradero, es una buena opción en pacientes que no son buenos candidatos para la cirugía ${ }^{(14)}$.

4. Miotomía quirúrgica, cirugía en la cual se debilita el EEI mediante la sección de fibras musculares, es el tratamiento más efectivo y duradero para la acalasia, sin embargo, se corre el riesgo de producir reflujo gastro-esofágico futuro, por lo que se suele acompañar de algún procedimiento antireflujo. La vía de abordaje hoy en día es principalmente laparoscópica o toracoscópica. El 85\% de los pacientes sometidos a cirugía evolucionan con importante disminución de los síntomas ${ }^{(13)}$.

Otra frecuente complicación de la cirugía es la perfo- ración esofágica, la que ocurre en aproximadamente un $5 \%$ de los pacientes, con una mortalidad de 1 en 1.574 casos reportados, la mayoría de éstas son reparadas intracirugía y las inadvertidas generalmente no presentan sintomatología ni mayor repercusión en los pacientes ${ }^{(13)}$.

El presente caso clínico es característico de una acalasia, sin embargo, se presenta a una edad muy poco frecuente y con consulta más precoz que lo habitual, ya que no es frecuente encontrar una disfagia en niños previamente sanos y con desarrollo normal. Podemos ver en este caso la importancia de la clínica y los exámenes de imágenes para llegar al diagnóstico. Con respecto a las imágenes, este caso nos confirma que la radiografía de esófago-estómago-duodeno es el mejor acercamiento inicial y en muchos casos suficiente para hacer el diagnóstico, y que además es el mejor examen para evaluar la posibilidad de perforación esofágica inadvertida y así tomar medidas para evitar las consecuencias de este evento adverso.

\section{Bibliografía}

1. Sadowski DC, Ackah F, Jiang B, Svenson LW. Achalasia: incidence, prevalence and survival. A population-based study. Neurogastroenterol Motil 2010; 22: e256-261.

2. Reynolds JC, Parkman HP. Achalasia. Gastroenterol Clin North Am 1989; 18: 223-255.

3. Goldblum JR, Whyte RI, Orringer MB, Appelman HD. Achalasia. A morphologic study of 42 resected specimens. Am J Surg Pathol 1994; 18: 327-337.

4. Goldblum JR, Rice TW, Richter JE. Histopathologic features in esophagomyotomy specimens from patients with achalasia. Gastroenterology 1996; 111: 648-654.

5. Wong RK, Maydonovitch CL, Metz SJ, Baker JR Jr. Significant DQw1 association in achalasia. Dig Dis Sci 1989; 34: 349-352.

6. Verne GN, Sallustio JE, Eaker EY. Anti-myenteric neuronal antibodies in patients with achalasia. A prospective study. Dig Dis Sci 1997; 42: 307-313.

7. Niwamoto H, Okamoto E, Fujimoto J, et al. Are human herpes viruses or measles virus associated with esophageal achalasia? Dig Dis Sci 1995; 40: 859-864.

8. Birgisson S, Galinski MS, Goldblum JR, et al. Achalasia is not associated with measles or known herpes and human papilloma viruses. Dig Dis Sci 1997; 42: 300-306.

9. Eckardt VF, Köhne U, Junginger T, Westermeier T. Risk factors for diagnostic delay in achalasia. Dig Dis Sci 1997; 42: 580-585.

10. Ott DJ, Richter JE, Chen YM, et al. Esophageal radiography and manometry: correlation in 172 patients with dysphagia. AJR Am J Roentgenol 1987; 149: 307-311.

11. Hirano I, Tatum RP, Shi G, et al. Manometric heterogeneity in patients with idiopathic achalasia. Gastroenterology 2001; 120: 789-798.

12. Gelfond M, Rozen P, Gilat T. Isosorbide dinitrate and nifedipine treatment of achalasia: a clinical, manometric and radionuclide evaluation. Gastroenterology 1982; 83: 963-969.

13. Campos GM, Vittinghoff E, Rabl C, et al. Endoscopic and surgical treatments for achalasia: a systematic review and meta-analysis. Ann Surg 2009; 249: 45-57.

14. Vantrappen G, Hellemans J. Treatment of achalasia and related motor disorders. Gastroenterology 1980; 79: 144-154. 